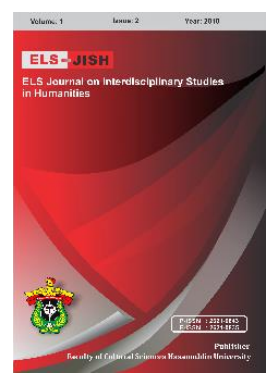

ELS-JISH

ELS Journal on Interdisciplinary Studies on Humanities

Volume 1 Issue 2, 2018

ISSN (print) : 2621-0843

ISSN (online) : 2621-0835

Homepage : http://journal.unhas.ac.id/index.php/jish

\title{
A Comparison of Rub Subtypes Verbs in English and Konjo Language
}

\author{
Syamsir ${ }^{1}$ \\ e-mail: syamsirelnino19@gmail.com
}

\begin{abstract}
This research focuses on Rub subtype verbs in and English Konjo language. The aims of the research were (1) to identify Rub subtype verbs in Konjo language and English. (2) to investigate the similarities and the differences of Rub subtype verbs in English and Konjo language in the aspect of semantic and grammatical construction. Furthermore, this research used descriptive qualitative method. English data were taken from COCA (Corpus of Contemporary American English). Meanwhile, Konjo language data were taken from observation and interview. Then, the results of this research indicated that (1) there are twelve Rub subtype verbs in English: rub, wipe, scrape, scratch, mark, sweep, brush, shave, rake, polish, lick and wash. Then, in Konjo language, there are nineteen verbs of Rub subtype: a'goso', assossoro, angngampallasa, a'lu'lu', angnga'ru' akkankang, angngara'musu, annanrai, a'ca' a'barrasa, assika', accukkuru, kokkoro, assumer, a'lemong, angngemu', a'bissa, assassa, and angngi'lasi. (2) The similiarities and the differences of Rub subtype verbs in English and Konjo language: The similarities are both of Rub subtype verbs in English and Konjo language can be applied in construction I (Agent + Target + Manip) and construction II (Agent + Manip + Target). The differences are the variant construction of English Rub subtype verbs and the extra constructions of Konjo language Rub subtype verbs. The variant construction of English Rub subtype verbs is variant construction lb (Agent + Target (Adj) + Manip) and extra constructions of Konjo language are extra construction la (Agent + Target), Ib (Target + Agent), lc (Agent + Target + Agent $),$ Id (Agent), le (Target + Agent) ${ }^{*}$, Ila (Agent + Target + Manip) ${ }^{*}$, Ilb (Manip + Agent + Target), IIla (Manip + Target + Manip) and IIlb (Manip + Manip + Target).
\end{abstract}

Keywords: : Rub Subtypes, Grammatical Construction, Semantic

How to cite: Syamsir. (2018). A Comparison of Rub Subtypes Verbs in English and Konjo Language. ELS Journal on Interdisciplinary Studies in Humanities, 1 (2), 162-169.

\section{Introduction}

Language is a way to make an interaction with other people. It can be used by person to person, group to group, person to group and group to person. Alduais (2012), stated that language is used by people to communicate with others. It is used in society, communities, regions and countries. According to Epoge (2013), language is a tool to be in contact with others. Moreover, Almurazhi (2016), explained that the uniqueness of every language is about morphology and syntax rules. Based on the explanation above, we can conclude that language is very important part in our life and cannot be separated in our life. Where we use it to share our feeling, ideas, thinking etc. On the other hand, every language has own characteristics itself. In the aspect of morphological and grammatical construction, there is no one language closely related to each other.

${ }^{1}$ Faculty of Cultural Sciences, Hasanuddin University 
Furthermore, by learning the language, especially about grammatical construction. It is not enough if we just pay attention to the grammatical construction of the sentence. Sentence is formed not just a random system, but it must follow the rule of it, e.g. I hit Dani and Dani hit me, it is correct. However, it is impossible to say I wash the motorcycle and the motorcycle wash me. Due to the fact, grammatical construction is interrelated with semantics. Semantic is study of meaning, we have to know the meaning of the sentence, so that, the sentence does not make us confuse. So, the grammatical construction of the sentence is formed by the meaning of it. According to Frense \& Bennet (1996), Syntax and Semantics are interrelated refers to the extent to which a word's syntactic behavior follows form its meaning. Next, Aslani (2013), explained that the right way to analyze the meaning of a word is to consider of its semantic and syntactic relations, and to recognize the grammatical constructions in which it participates. Moreover, R.M.W Dixon made a new approach to modern grammar, he used semantic approach to make the grammatical construction of the sentence.

Verb is the main part of the sentence. It has main role to convey the meaning of the sentence. Dixon (2005), divided verb into motion verb, rest verb, affect verb and giving verb. Furthermore, Affect verb is a class of verbs to make an effect with the target. There are three semantic roles of Affect verb: Agent (someone or somebody who do the action), Manip (something which used by the agent to make an effect with the target, and Manip always touched each other with the target), Target (something which is accepted an effect). Next, the syntactic role of Affect verb: if transitive verb, there are two or more roles, A (transitive subject) and $O$ (transitive object) and if intransitive, only one role, $S$ (intransitive subject). Moreover, the basic constructions of Affect verb: construction I, II, and III, e.g. construction I, e.g. John (Agent) hit the chair (Target) with that stick (Manip), construction II, e.g. I (Agent) hit that stick (Manip) into the table (Target), construction III, e.g. The rain (Manip) wash my hair (Target). Based on the example, we conclude that construction I is focus on the target, construction II is focus on the manip and construction III is the unique construction, there is no Agent. Construction III happen when someone did not do it on purpose or naturally.

One of the class of Affect verb is rub subtype. Dixon (2005), defined that Rub subtype is a class of verb to make an effect with the surface of the target e.g. rub, wipe, scrape, scratch, mark, sweep, brush, shape, rake, polish, lick and wash. Furthermore, the grammatical constructions of Rub subtype: construction I (Agent + Target + Manip), II (Agent + Manip + Target), III is possible (Manip + Target), IV (Agent + (prep) Target + Manip), construction IV is only plausible and the variant of construction I, where there is preposition before the Target, and there are also two other variants of construction I, those are: variant construction la (Agent + Target (prep) NP), variant construction lb (Agent + Target (Adj) + Manip) and variant construction IVb (Agent + (prep) Target (prep) NP + Manip). Unfortunately, Dixon did not mention the specific part to use all of the construction, like in spoken, fiction, magazine, newspaper etc.

Based on the Dixon's theoretical framework, is all of the constructions suitable to apply in conversation? And is the theory can be used in another language? Since we know that every language has the uniqueness itself. Therefore, the researcher is interested to compare Rub subtype verbs in English and Konjo language in the aspect of spoken.

Konjo language is one of the local language in South Sulawesi and as one branch of Malayo-Polinesian. It has sub family with Makassarese and Selayarnese. Ningsih (2016), stated that the people who used Konjo language live in the east side of Bulukumba 
regency, especially in Bonto Bahari sub district, Bonto Tiro sub district, Herlang sub district and Kajang subdistrict.

There are some previous studies are related to this research. Nakhavaly (2012), focused on the analysis of grammatical voice in the short story "the setar". Mohammadpour (2012), concerned with examination of verb and verb phrase in Boier Ahmadi lori based on X-bar Syntax. Next, Fu (2016), focused on semantic fuzziness and tts translation strategies. Itagaki (2017), concern with complement of the sound-class verb construction. Then, the last, Asrumi (2014), the semantic relation of denominal, deverbal, and deadjectival verbs with other arguments in the Osing language However, all of the previous studies do not investigate Rub subtype verbs refer to Dixon's theory. This research focused on Rub subtype verbs in English and Konjo Language. The aims of this research is to assist the readers who want to study both English and Konjo language, particularly in semantics and grammar.

\section{Method}

The researcher used descriptive qualitative method to get the data. Furthermore, this research explained the similarities and differences of Rub subtype verbs in English and Konjo refer to the aspect of semantic and grammatical construction.

\subsection{Data Collection}

The data of this research focus on Rub subtype verbs in English and Konjo language. English data was collected on Corpus of Contemporary American English (COCA), corpus.byu.edu//coca. The researcher chose spoken section to make it relevant with Konjo language data. Then, Konjo language data was collected by doing observation and interview. Addition, the researcher used in-depth interview to get information about Konjo language data by asking the people who use Konjo language as their first language.

\subsection{Data Analysis}

By analyzing the data, the researcher used some techniques. Firstly, collecting English data on COCA and the Konjo language data was collected by doing observation and in-depth interview. Secondly, the collected data reduced, the researcher reduced English and Konjo language data which have been collected. Then, presenting the data, the data based on Rub subtype verbs in English and Konjo were presented and compared in the aspect of semantic and grammatical construction. Next, analysing the data, the data were analyzed by using Dixon's theory. The researcher determined the meaning of Rub subtype verbs in English by using Oxford Dictionary, whereas the meaning of Rub subtype verbs in Konjo language were concluded based on the information by doing observation and in-depth interview. Finally, concluding the result of research, after doing the analysis, the researcher made some conclusions as the main points of the analysis.

\section{Findings}

There are twelve Rub subtype verbs in English, while in Konjo language, there are nineteen verbs. Since there are some verbs of Konjo language that has only one meaning in English, e.g. wash is equivalent with a'bissa, assassa and angngi'lasi. A'bissa itself has two roles, a'bissa (transitive) means to wash something like motorcycle, car, shoes, slippers, rice etc. And a'bissa (intransitive) means to wash genital or anus. Assassa means to wash the laundry and angngilasi means to wash the kitchenware. Rub verb also has three meaning in Konjo language, those are: a'goso, 'rub something like table, chair, 
kitchen ware etc.' and assossoro 'rub the body', and the last angngampallasa 'rub something which made from wood by using sand paper to make it soft', angngampallasa verb derives from noun ampallasa which means sand paper. Mark verb has to meaning in Konjo language, they are: annanrai 'making a mark in the surface of the target by using pen or something sharp'and a'ca' 'mark something by using special tool' it usually use for making mark to the kitchenware. Shave verb has two meaning in konjo language: accukkuru 'cut hair of head' and kokkoro 'cut hair of body by using a razor'.

Next, Polish verb also has two meaning in Konjo language: Assumer means making the target (shoes) glossy and it is derived from noun sumer. And a'lemong means 'making something glossy like furniture, motorcycle, etc. However, there are some verbs of Rub subtype in English that has only one meaning in Konjo language. Those are: wipe means "clean or dry something with a cloth, a piece of paper or one's hand' equivalent with a'lu'lu', scrape refers to 'drag or pull a hard or sharp implement across to the surface of the object so as to remove dirt or other matter' equivalent with annga'ru', scratch means 'rub (a part of one's body) with one's fingernails' equivalent with akkankang, Sweep means 'clean an area by using broom' equivalent with a'barrasa, Brush verb has reference 'use a brush to remove dust or dirt from something' equivalent with assika', Rake means 'scratching something, especially a person's flesh with a long sweeping movement' equivalent with angngara'musu, Lick means pass the tongue over (something in order to taste, moisten, or clean it) equivalent with angngemu'.

The grammatical construction of Rub subtype verbs in English and Konjo language based on the Dixon's theory and limited to the spoken section. Rub subtype verbs in English refers to the data was taken from COCA. All of the verbs that applied in construction I : rub, wipe, scrape, scratch, rake, polish, lick, wash, mark, sweep, brush and shave. The syntactic role of construction I, (Agent + Manip + Target) can be seen in the table 1. Furthermore, some verbs that applied in construction II: rub, scrape and scratch. Furthermore, Rub subtype verbs in Konjo language refers to the data was taken from observation and interview in the field of research. The syntactic role of construction II, (Agent + Manip + Target) as shown in the table 1. Next, almost all of Rub subtype verbs in Konjo language can be applied in construction I: assossoro, angngampallasa, a'lu'lu', angnga'ru', akkankang, angngara'musu, assumer, a'lemong, angngemu', assassa, a'bissa, annanrai, a'ca', a'barrasa, assika', accukkuru and kokkoro, except angngi'lasi. Addition, there are some verbs in Konjo language can be applied in construction II, they are a'lu'lu', angnga'ru' and assika'.

Moreover, there are some verbs of English Rub subtype can be applied in variant construction lb, e.g. wipe, scrape, sweep and wash. The syntactic role of variant construction lb, (Agent + Target (Adj) + Manip) can be seen in the table 1 .

Table 1. Construction I, II, variant construction Ib, and extra construction le of Rub subtype verbs in English and Konjo Language 
ISSN: (E) 2621-0835, (P) 2621-0843

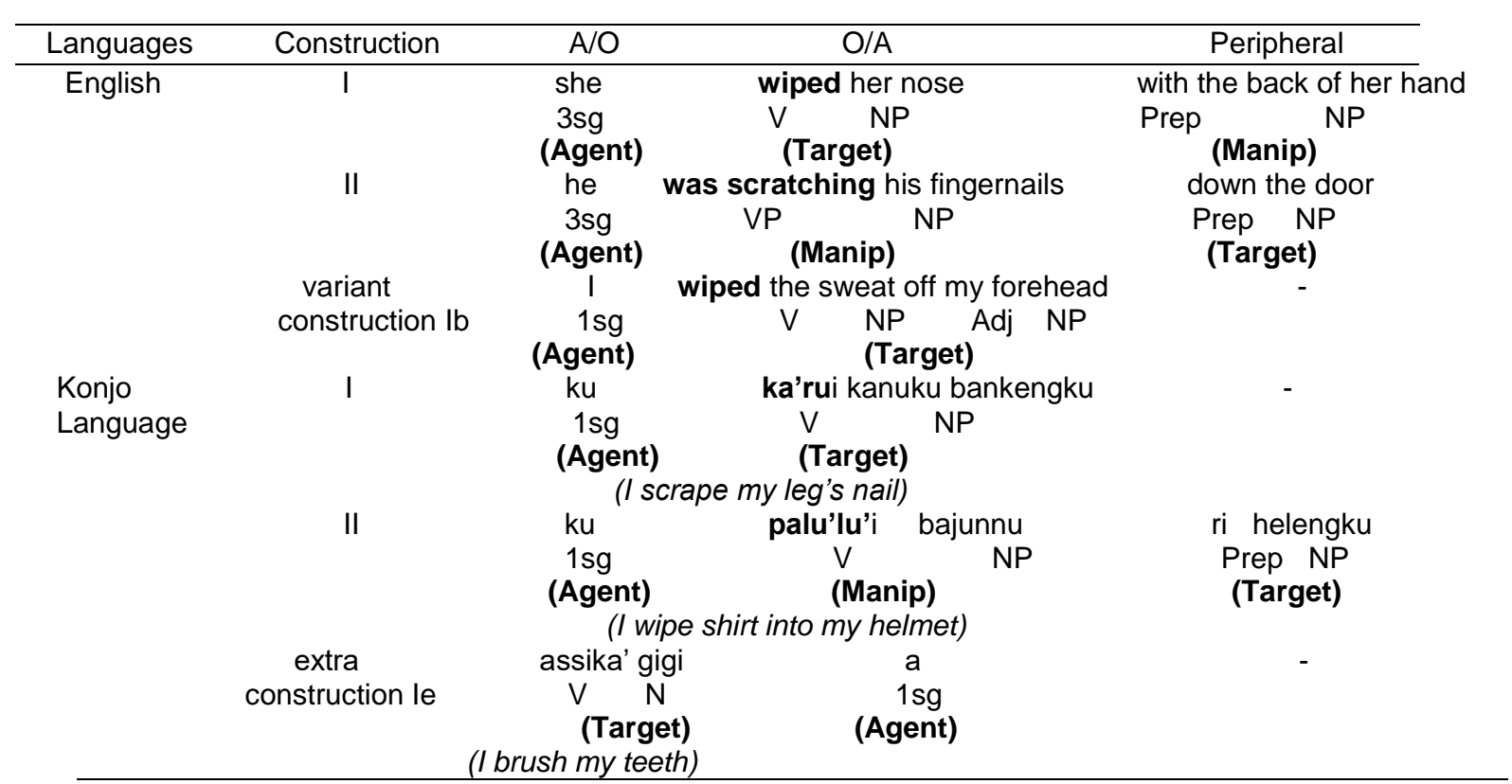

However, variant construction la is not available in Konjo language. Whereas, there are some new construction Rub subtype verbs in Konjo language and cannot be applied in English. Such as: extra construction la, Ib, Ic, Id, le, Ila, Ilb, IIla and IIlb. Next, the Rub subtype verbs which can be applied in extra construction la: a'goso', angngampallasa, a'lu'lu', angnga'ru', annanrai, a'barrasa, assika', angngemu, a'bissa, a'lemong, assumer. The syntactic role of extra construction la, (Agent + Target) as shown in the table 2.

Table 2. Extra construction la, Ib, Ic, Ilb, and IIla of Konjo Language

\begin{tabular}{|c|c|c|c|c|c|}
\hline Languages & Construction & $\mathrm{A} / \mathrm{O}$ & $\mathrm{O} / \mathrm{A}$ & $\mathrm{A} / \mathrm{O}$ & Peripheral \\
\hline English & - & - & - & - & - \\
\hline \multirow[t]{12}{*}{ Konjo Language } & extra & a'lu'lu' & a & mejang & - \\
\hline & construction la & (I w & $\begin{array}{l}1 \mathrm{sg} \\
\text { (Agent) } \\
\text { pe the table) }\end{array}$ & $\begin{array}{c}\mathrm{N} \\
\text { (Target) }\end{array}$ & \\
\hline & extra & kollang andeke & $\mathrm{ku}$ & ka'ru' & - \\
\hline & construction lb & $\begin{array}{c}\mathrm{NP} \\
\text { (Target) }\end{array}$ & $\begin{array}{c}1 \mathrm{sg} \\
\text { (Agent) }\end{array}$ & V & \\
\hline & \multicolumn{5}{|c|}{ (I scrape this pool) } \\
\hline & extra & na & Iulu’i mejanna & Basse & \multirow{4}{*}{$\begin{array}{l}\text { ri motorokku } \\
\text { Prep NP } \\
\text { (Target) }\end{array}$} \\
\hline & construction lc & $\begin{array}{c}3 s g \\
\text { (Agent) }\end{array}$ & $\begin{array}{l}\mathrm{V} \quad \mathrm{NP} \\
\text { (Target) }\end{array}$ & $\begin{array}{c}3 s g \\
\text { (Agent) }\end{array}$ & \\
\hline & extra & Baju toa & $\mathrm{ku}$ & palu'lu' & \\
\hline & construction Ilb & $\begin{array}{l}\text { NP } \\
\text { (Manip) } \\
\quad \text { (I rubbed }\end{array}$ & $\begin{array}{c}1 \mathrm{sg} \\
\text { (Agent) } \\
\text { he old shirt into }\end{array}$ & $\begin{array}{c}\mathrm{V} \\
\text { my motorcycle) }\end{array}$ & \\
\hline & extra & na & ka'ru' a & paku & \multirow[t]{3}{*}{ - } \\
\hline & construction IIla & $\begin{array}{c}1 \mathrm{sg} \\
\text { (Manip) }\end{array}$ & 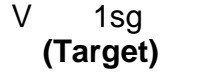 & $\begin{array}{c}\mathrm{N} \\
\text { (Manip) }\end{array}$ & \\
\hline & \multicolumn{4}{|c|}{ (The nail scraped me) } & \\
\hline
\end{tabular}

In extra construction lb: a'goso', angngampallasa, a'lu'lu', angnga'ru, akkankang, annanrai, a'barrasa, assika, angngara'musu, assumer, a'lemong, a'bissa. The syntactic role of extra construction lb (Target + Agent) can be seen in the table 2 . In extra construction Ic: a'goso', angngampallasa, a'lu'lu', angnga'ru', akkankang, annanrai, a'barrasa, assika', kokkoro, accukkuru, angngara'musu, assumer, a'lemong, angngemu', 
a'bissa. The syntactic role of extra construction lc, (Agent + Target + Agent) as shown in the table 2. In extra construction Id: assossoro, akkankang, accukkuru, assassa, angngi'lasi. In extra construction le: assika' and a'bissa. The syntactic role of extra construction le (Target + Agent) can be seen in table 1. In extra construction Ila: a'lu'lu, angnga'ru' and assika'. The syntactic role of extra construction Ila, (Agent + Target + Manip) as shown in the table 3.

Table 3. Extra construction Ila of Konjo Language

\begin{tabular}{|c|c|c|c|c|c|}
\hline Languages & Construction & $A$ & 0 & Peripheral & 0 \\
\hline $\begin{array}{l}\text { English } \\
\text { Konjo Language }\end{array}$ & $\begin{array}{l}\text { extra } \\
\text { construction Ila }\end{array}$ & $\begin{array}{c}\mathrm{ku} \\
1 \mathrm{sg} \\
\text { (Agent) } \\
\text { (I wiped }\end{array}$ & $\begin{array}{c}\text { palu'lu'i } \\
\mathrm{V} \\
\text { your feather }\end{array}$ & $\begin{array}{c}\text { ri oto } \\
\text { Prep N } \\
\text { (Target) } \\
\text { n the car) }\end{array}$ & $\begin{array}{c}\text { kemocengnu } \\
\text { NP } \\
\text { (Manip) }\end{array}$ \\
\hline
\end{tabular}

In extra construction Ilb: a'lu'lu', angnga'ru', assika'. The syntactic role of extra construction Ilb, (Manip + Agent + Target) can be seen in the table 2. In extra construction IIla: angnga'ru. The syntactic role of extra construction IIla, (Manip + Target + Manip) as shown in the table 4. Then the last, in extra construction IIIb: angnga'ru'. The syntactic role of extra construction IIIb, (Manip + Manip + Target) as shown in the table 4.

Table 4. Extra construction Illb of Konjo Language

\begin{tabular}{ccccccc}
\hline Languages & Construction & $\mathrm{A}$ & $\mathrm{O}$ & $\mathrm{A}$ & $\mathrm{O}$ & Peripheral \\
\hline English & extra & na & ka'ru'i & paku & bajungku & - \\
Konjo language & construction Illb & $\begin{array}{c}3 s \mathrm{sg} \\
\text { (Manip) } \\
\text { (The nail scraped my shirt) }\end{array}$ & $\mathrm{V}$ & $\begin{array}{c}\mathrm{N} \\
\text { (Manip) }\end{array}$ & $\begin{array}{c}\text { NP } \\
\text { (Target) }\end{array}$ & \\
\hline
\end{tabular}

The syntactic role of extra construction Id, (Agent) can be seen in the table 5 .

Table 5. Extra construction Id of Konjo Language

\begin{tabular}{cccc}
\hline Languages & Construction & $\mathrm{S}$ \\
\hline English & & & \\
Konjo Language & extra & angngi'lasi & $\mathrm{a}$ \\
& construction Id & $\mathrm{V}$ & $\begin{array}{c}\text { 1sg } \\
\text { (Agent) }\end{array}$ \\
& & (I wash the kitchenware) \\
\hline
\end{tabular}

\section{Discussion}

Based on the findings above, the researcher found that there are twelve Rub subtypes verbs can be applied in spoken construction refers to the Dixon's theory and the data was collected on COCA. Such as: rub, wipe, scrape, scratch, mark, sweep, brush, shave, rake, polish, lick and wash. In Konjo language, there are nineteen verbs refer to Rub subtype. Those are assossoro, angngampallasa, a'lu'lu', angnga'ru', akkankang, angngara'musu, assumer, a'lemong, angngemu', assassa, a'bissa, annanrai, a'ca', a'barrasa, assika', accukkuru and kokkoro, except angngi'lasi. Furthermore, in 
semantically two or more verb have same meaning or equivalent with one verb in English. Such as: assossoro, angngampallasa, a'lu'lu' equivalent with rub, a'lu'lu' equivalent with wipe, angnga'ru', equivalent with scrape, akkankang equivalent with scratch, angngara'musu equivalent with rake, assumer and a'lemong equivalent with polish, annanrai and a'ca' equivalent with mark, a'barrasa equivalent with sweep, assika equivalent with brush, accukkuru and kokkoro equivalent with shave, a'bissa, anngilasi and assassa equivalent with wash.

Grammatically, Rub subtype verbs in English and Konjo language can be applied in Construction I and II. However, variant construction Ib can be applied in English Rub subtype verbs and not available in Konjo language. Whereas, extra construction la, lb, lc, Id, le, Ila, Ilb, IIla and IIIb can be applied in Konjo language Rub subtype verbs and not available in English. It is about the characteristic of the language itself.

\section{Conclusion}

This research consists of the similarities and differences between Rub subtype verbs of English and Konjo languages in the aspect of semantic and grammatical construction. This research also was limited to spoken data section to make it relevant with Konjo language data. Furthermore, the similarities and the differences of Rub subtype verbs in English and Konjo language in two aspects: firstly, in the aspect of semantic, there are twelve verbs of Rub subtype verbs in English, however in Konjo language, there are nineteen verbs. It depends on the meaning. Secondly, the similarity of Rub subtype verbs of English and Konjo language in the aspect of grammatical construction: Both of Rub subtype verbs in English and Konjo language can be applied in construction I and II. However, construction I in konjo language data, Manip is not available. Then the differences of Rub subtype verbs of English and Konjo language in the aspect of grammatical construction: variant construction lb can be applied in English and it is not available in the construction of Konjo data. Whereas, there are some new construction of Rub subtype verbs in Konjo language. Then, the researcher named it: Extra construction Ia, Ib, Ic, Id, Ie, Ila, Ilb, IIla and IIlb. All of the extra constructions cannot be applied in English. It is about the characteristic of Konjo language. Based on the data above, Semantics and Syntax are very interrelated, because Syntax was built by the meaning of the sentence. Then, refers to Dixon's theory, Even though, Dixon's theory could prove that the construction I and II can be applied in Konjo language Rub subtype verbs. However, his theory cannot cover the extra constructions of Konjo language. Finally, this research very useful to people who want to study Semantics, grammar and Syntax.

\section{References}

Alduais S M A. (2012). Simple Sentence Structure of Standard Arabic Language and Standard English Language. International Journal of Linguistics, 4(4): 500-524

Almurhazi A. (2016). Simple Analysis and Critical Refletion of the Morphologhy and Syntax of Acehnese language. Journal for the Study of English Linguistic, 4(1): 31-40

Aslani R M. (2013). Frame Semantics, Metalexicography and the Microstructure of Persian Monolingual Dictionaries. International Journal of Linguistics, 5(3): 99-114

Asrumi. (2014). The Semantic Relation of Denominal, Deverbal, and Deadjectival Verbs with Other Arguments in The Osing Language. International Journal of Linguistics, 6(2): $62-80$ 
Dixon R M W. (2005). A Semantic Approach to English Grammar. Second Edition. New York: Oxford University Press

Epoge K N. (2013). Slang and Colloquialism in Cameroon English Verbal. International Journal of Linguistics, 4(1): 130-145

Frense J. \& Bennet P. (1996). Verb Alternations and Semantics Classes in English and German. Journal Language Science, 18(1-2): 305-317

Fu. (2016). Semantic fuzziness and It's translation strategies. International Journal of Linguistics, 8(2): 199-208

Itagaki. (2017). Complement of The Sound-Class Verb Construction. Journal for the Study of English Linguistics, 5(1): 29-41

Mohammadpour F. (2012). Examination of Verb and Verb Phrase in Boier Ahmadi Lori Based on X-bar Syntax. International Journal of Linguistics, 4(3): 509-522

Nakhavaly F. (2012). The Analysis of Grammatical Voice in the Short Story "The Setar". International Journal of Linguistics, 4(4): 171-179

Ningsih S. (2016). Factors Contributing to the Maintenance of Konjo language in Heteregenous area of Bulukumba Regency. Journal Ethical Lingua, 3 (2): 103-113 